\title{
Systematic Review and Meta-analysis:Real-world Data Rates of Deep Remission With Anti-TNFa in Inflammatory Bowel Disease
}

\author{
Omeed Alipour \\ University of Washington https://orcid.org/0000-0002-3059-0561 \\ Alakh Gulati \\ University of California San Francisco Fresno Center for Medical Education and Research \\ Ling Shao \\ University of Southern California Keck School of Medicine \\ Bing Zhang ( $\sim$ Bing.zhang@ucsf.edu ) \\ University of California San Francisco
}

Research article

Keywords: Remission, inflammatory bowel disease, Crohn's disease, ulcerative colitis, tumor necrosis factor-a inhibitor

Posted Date: November 23rd, 2020

DOI: https://doi.org/10.21203/rs.3.rs-112698/v1

License: (우 This work is licensed under a Creative Commons Attribution 4.0 International License. Read Full License

Version of Record: A version of this preprint was published at BMC Gastroenterology on August 3rd, 2021. See the published version at https://doi.org/10.1186/s12876-021-01883-6. 


\section{Abstract}

\section{Background \& Aims}

Deep remission (DR) is a treatment target in IBD associated with reduced hospitalization and improved outcome. Randomized control trial (RCT) data demonstrates efficacy of anti-TNFa agents in achieving DR; however, RCTs may not be generalizable to clinical practice. In this systematic review with meta-analysis, we use real-world data (RWD) to determine rates of DR in IBD treated with anti-TNFa.

\section{Methods}

We completed a systematic search of MEDLINE and EMBASE on July 8, 2019 with review of major gastrointestinal conference abstracts from 2012-2019. Studies utilizing RWD (data not from phase I-III RCTs) of adult IBD patients treated with anti-TNFa agents were included. DR was defined by clinical and endoscopic remission at minimum. DR was assessed at 8 weeks, 6 months, 1 year, and 2 years.

Results

29,033 publications were found on initial search. Fifteen publications, nine manuscripts and six conference abstracts, were included encompassing 1,212 patients (769 Crohn's disease-CD, 443 ulcerative colitis-UC). Rate of DR was 36.4\% (95\%-Cl: 12.6-69.4\%) at eight weeks, 39.1\% (95\%-Cl: 10.4-78\%) at six months, $44.4 \%$ (95\%-Cl: 34.6-54.6\%) at one year, and 36\% (95\%-Cl: $18.7-58 \%)$ at two years. DR in CD at one year was 48.6\% (95\%-Cl: 32.8-64.7\%) and in UC was 43.6\% (95\%-Cl: 32.8-55.1\%).

\section{Conclusions}

The rate of DR was highest after one year of therapy, in nearly 45\% of IBD patients treated with anti-TNFa. Similar rates were achieved between patients with UC and CD. The findings highlight the efficacy of anti-TNFa in real-world setting. Future studies using RWD can determine efficacy of newer IBD therapeutics in routine clinical practice.

\section{Background}

Deep remission (DR) is a proposed treatment target in inflammatory bowel disease (IBD) that is increasingly being used as a benchmark in efficacy studies and randomized controlled trials (RCT). ${ }^{1}$ The most common definition for DR is concurrent clinical remission (CR) and endoscopic remission (ER) or mucosal healing (MH). ${ }^{2} \mathrm{DR}$ is associated with longer periods of durable remission, improvement in quality of life, reduced hospitalization, and a decreased rate of surgical complications. ${ }^{3-6}$ Therefore, $^{-}$ there is great interest in determining the rate of achieving DR with various treatment strategies.

Recent meta-analysis examined the rate of achieving DR with anti-TNFa agents in randomized controlled trials (RCTs) among ulcerative colitis (UC) patients, ${ }^{7}$ but none have evaluated DR in a real-world environment or in patients with Crohn's disease (CD). Differences between the efficacy of a drug's performance during a clinical trial and its effectiveness during use in everyday clinical practice has been described as the "efficacy-effectiveness gap." ${ }^{8}$ RCTs, though the ideal study design to demonstrate effectiveness and safety of a medication, are carried out in selective and controlled manner leading to high internal validity, but leaving uncertainty about their generalizability for an ethnically diverse and heterogenous population. ${ }^{9}$ This possible lack of generalizability has also been demonstrated within the IBD population, ${ }^{10}$ and therefore creates a role for real world data (RWD) to fill. ${ }^{11}$

In this systematic review with meta-analysis, we aim to provide complementary information by using RWD to determine rates of deep remission in IBD with anti-TNFa agents in clinical practice. Additionally, we perform sub-analyses to provide the rates of DR with anti-TNFa separately in patients with CD and UC. Furthermore, we explored the treatment duration at which DR is most likely to be seen, and the rate of DR in patients not previously treated with anti-TNFa.

\section{Methods}

The current study was performed in accordance with the PRISMA statement. ${ }^{12}$ 


\subsection{Data sources and searches}

We completed a systematic search of MEDLINE and EMBASE up to July 8, 2019 (see Appendix for search strategy), using the following search terms: ("inflammatory bowel disease" OR "IBD" OR "crohn*" OR "ulcerative colitis" OR "UC" or "colitis") AND ("mucosal healing" OR "deep remission" OR "complete remission" OR "full remission" OR "endoscopic remission"). This search was conducted without restrictions on year or language. We manually searched through abstracts presented at major national and international gastrointestinal conferences from 2012-2019 (Digestive Disease Week, United European Gastroenterology Week, European Crohn's and Colitis Organization, the American College of Gastroenterology Annual Scientific Meeting, Advances in Inflammatory Bowel Diseases, and the Crohn's and Colitis Congress). The reference sections of manuscripts included were also reviewed for additional studies to be evaluated for inclusion. Two authors (OA and AG) independently conducted this review. A third author (BZ) reviewed studies not agreed upon for inclusion.

\subsection{Selection criteria}

We included studies that presented real world data (RWD)/real world evidence (RWE), defined as all health data except those collected in a conventional phase I, II, or III RCT setting. We included studies examining adults (18 years or older) with inflammatory bowel disease treated with anti-TNFa agents until the achievement of "deep remission" (DR), defined as at least a combination of clinical remission and mucosal healing/endoscopic remission. ${ }^{2}$ Search results were carefully reviewed to identify remission targets consistent with common definitions of deep remission given many did publications did not explicitly state the term "deep remission" as an end point.

Case reports, case series, randomized trials, and non-English studies were excluded. Studies that did not define DR or did not identify components of DR to include at least clinical and endoscopic remission were excluded. Studies with a pediatric population were excluded to maintain a focus on adult patients.

The primary outcome was real-world rates of DR with anti-TNFa agents for the treatment of IBD at intervals of 8 weeks, six months, one year and two years after starting anti-TNFa. Secondary outcomes included rates of DR among UC and CD at one year after starting anti-TNFa, the rates of DR in patients naïve to, or not previously treated with, anti-TNFa, and the rates of DR with infliximab.

\subsection{Data extraction and risk of bias assessment}

Two authors ( $O A$ and $A G)$ independently extracted the following data onto a data collection form: first author's name, last author's name, publication year, country, single or multiple institutions, study design, type of IBD, type of anti-TNFa used, concomitant or maintenance therapy, definition of deep remission, definition of mucosal healing/endoscopic remission, definition of clinical remission, and the number of participants who achieved deep remission at pre-determined time points ( 8 weeks, 6 months, 1 year, and 2 years).

All studies were deemed cohort studies based on the intervention of interest (treatment with anti-TNFa agents). Risk of bias was assessed independently by two authors (OA and AG) using the Newcastle-Ottawa Scale. ${ }^{13}$ Any inconsistencies between the authors' scores were discussed and resolved. Out of nine possible stars, studies were considered at high risk of bias if they received $0-3$ stars, intermediate risk if 4-6 stars, and low risk if 7-9 stars.

\subsection{Data synthesis}

To account for anticipated inherent heterogeneity in the designs of the included studies (for example, retrospective versus prospective, definitions of deep remission, anti-TNFa agents used, patient populations, etc.), pooled event rates and corresponding 95\% confidence intervals $(95 \% \mathrm{Cl}$ ) were calculated using the random-effects model per DerSimonian and Laird and inverse variance method for dichotomous outcomes. ${ }^{14}$ Between-study heterogeneity was assessed with the chi-square test with significance defined as $p<0.1$, and the $I^{\wedge} 2$ test at $>50 \% .{ }^{15}$ Publication bias was assessed with funnel plot and Egger test. All analyses were performed using Comprehensive Meta-Analysis (version 3; Biostat, Englewood, NJ, USA, 2013). 


\section{Results}

\subsection{Search results}

The search strategy identified 29,033 publications. After a review of titles, abstracts, and exclusion of duplicates, 756 articles underwent thorough review (Fig. 1). Application of the exclusion criteria yielded fifteen studies (9 manuscripts, 6 conference abstracts), encompassing a total of 1,212 patients (Table 1). ${ }^{16-30}$ A diagnosis of CD was captured for 769 patients, and a diagnosis of UC was provided for 443 patients. 
Table 1

Characteristics of studies included in meta-analysis.

\begin{tabular}{|c|c|c|c|c|c|c|c|c|c|}
\hline \multirow[t]{2}{*}{ Study } & \multirow[t]{2}{*}{ Country } & \multirow[t]{2}{*}{$\begin{array}{l}\text { Study } \\
\text { design }\end{array}$} & \multirow[t]{2}{*}{ DR criteria } & \multicolumn{2}{|c|}{$\begin{array}{l}\text { Patients } \\
\text { evaluated } \\
\text { for DR }\end{array}$} & \multirow[t]{2}{*}{ Anti-TNF } & \multirow[t]{2}{*}{$\begin{array}{l}\text { Concomitant } \\
\text { Therapeutics }\end{array}$} & \multirow[t]{2}{*}{$\begin{array}{l}\text { Time of DR } \\
\text { assessment }\end{array}$} & \multirow[t]{2}{*}{$\begin{array}{l}\text { Prior } \\
\text { Anti-TNF } \\
\text { Use }\end{array}$} \\
\hline & & & & UC & CD & & & & \\
\hline $\begin{array}{l}\text { Sebkova } \\
2012\end{array}$ & $\begin{array}{l}\text { Czech } \\
\text { Republic }\end{array}$ & Retro & $\begin{array}{l}\text { CDAl<150, } \\
\text { no mucosal } \\
\text { ulcerations }\end{array}$ & - & 60 & $\begin{array}{l}\mathrm{IFX}^{\dagger} \text { or } \\
\mathrm{ADA}^{\ddagger}\end{array}$ & $\begin{array}{l}\text { IMM§ (not } \\
\text { specified, } \\
\text { used in } \\
30 / 60 \text { ) }\end{array}$ & 1 year & $\begin{array}{l}\text { Yes } \\
(17 / 60)\end{array}$ \\
\hline $\begin{array}{l}\text { Vadan } \\
2012\end{array}$ & Romania & Pro & $\begin{array}{l}\text { CDAl<150, } \\
\text { no mucosal } \\
\text { ulcerations }\end{array}$ & - & $49 *$ & $\mathrm{IFX}^{+}$ & IMM§ (5/49) & 1 year & No \\
\hline $\begin{array}{l}\text { Vadan } \\
2013\end{array}$ & Romania & Pro & $\begin{array}{l}\text { CDAl<150, } \\
\text { no mucosal } \\
\text { ulcerations }\end{array}$ & & $49 *$ & $\mathrm{IFX}^{+}$ & $\mathrm{IMM}^{\S}(5 / 49)$ & 6 months & No \\
\hline $\begin{array}{l}\text { De Vos } \\
2013\end{array}$ & Belgium & Pro & $\begin{array}{l}\text { Partial Mayo } \\
<3 \text {, endo } \\
\text { Mayo } 0\end{array}$ & 87 & - & $\mathrm{IFX}^{+}$ & $\begin{array}{l}\text { AZA } \\
(60 / 87)\end{array}$ & 1 year & No \\
\hline $\begin{array}{l}\text { Molander } \\
2013\end{array}$ & Finland & Retro & $\begin{array}{l}\text { No clinical } \\
\text { symptoms, } \\
\text { SES-CD 0-2, } \\
\text { endo Mayo } \\
0-1\end{array}$ & 69 & 183 & $\begin{array}{l}\mathrm{IFX}^{\dagger} \text { or } \\
\mathrm{ADA}^{\ddagger}\end{array}$ & $\begin{array}{l}\text { AZA } \\
(140 / 252), \\
6 M P \\
(23 / 252), \\
\text { MTX } \\
(22 / 252)\end{array}$ & 2 year & $\begin{array}{l}\text { Not } \\
\text { specified }\end{array}$ \\
\hline Dai 2014 & China & Pro & $\begin{array}{l}\text { CDAl }<150 \text {, } \\
\text { Mayo }<2, \\
\text { SES-CD 0-3, } \\
\text { endo Mayo } 0\end{array}$ & 107 & 109 & $\mathrm{IFX}^{+}$ & $\begin{array}{l}\mathrm{IMM}^{\S} \\
\text { (66/109 CD, } \\
34 / 107 \text { UC) }\end{array}$ & 1 year & $\begin{array}{l}\text { Yes }(17 \\
\text { CD, } 3 \\
\text { UC) }\end{array}$ \\
\hline $\begin{array}{l}\text { Echarri } \\
2015\end{array}$ & Spain & Pro & $\begin{array}{l}\mathrm{HBI}<5 \text {, SES- } \\
\mathrm{CD} 0-2\end{array}$ & - & 64 & $\mathrm{ADA}^{\ddagger}$ & $\begin{array}{l}\text { AZA } \\
\text { (44/68), } \\
\text { steroids } \\
(56 / 68)\end{array}$ & $\begin{array}{l}6 \text { months, } 1 \\
\text { year, } 2 \text { year }\end{array}$ & No \\
\hline Yu 2015 & China & Retro & $\begin{array}{l}\text { CDAI < 150, } \\
\text { SES-CD 0-2 }\end{array}$ & - & 106 & $\mathrm{IFX}^{\dagger}$ & $\begin{array}{l}\text { AZA } \\
(49 / 106)\end{array}$ & 8 weeks & No \\
\hline $\begin{array}{l}\text { Magro } \\
2016\end{array}$ & Portugal & Pro & $\begin{array}{l}\text { Mayo 0-2, } \\
\text { endo Mayo } \\
0-1 \text {, Geboe's } \\
\text { score }<4\end{array}$ & 20 & - & $\mathrm{IFX}^{\dagger}$ & $\begin{array}{l}\text { AZA } \\
(17 / 20)\end{array}$ & $\begin{array}{l}8 \text { weeks, } 6 \\
\text { month, } \\
1 \text { year }\end{array}$ & No \\
\hline $\begin{array}{l}\text { Pineton de } \\
\text { Chambrun } \\
2016\end{array}$ & France & Retro & $\begin{array}{l}\text { Clinical } \\
\text { physician } \\
\text { assessment, } \\
\text { no ulcerations }\end{array}$ & - & 67 & $\mathrm{IFX}^{\dagger}$ & $\begin{array}{l}\text { AZA } \\
(26 / 67)\end{array}$ & 2 year & No \\
\hline $\begin{array}{l}\text { Prymak } \\
2016\end{array}$ & Ukraine & Pro & $\begin{array}{l}\text { CAl and } \\
\text { UCEIS (not } \\
\text { defined) }\end{array}$ & 51 & - & $\mathrm{IFX}^{\dagger}$ & $\begin{array}{l}\text { Mesalamine } \\
\text { + steroids } \\
(25 / 51)\end{array}$ & 8 weeks & No \\
\hline $\begin{array}{l}\text { Zhang } \\
2016\end{array}$ & China & Pro & $\begin{array}{l}\text { CDAI }<150 \text {, } \\
\text { no ulcerations }\end{array}$ & - & 22 & $\mathrm{IFX}^{\dagger}$ & None & $\begin{array}{l}6 \text { month, } 1 \\
\text { year, } 2 \text { year }\end{array}$ & No \\
\hline
\end{tabular}

(†: infliximab; ‡: adalimumab; §: immunomodulators; 9 : azathioprine) 


\begin{tabular}{|c|c|c|c|c|c|c|c|c|c|}
\hline \multirow[t]{2}{*}{ Study } & \multirow[t]{2}{*}{ Country } & \multirow[t]{2}{*}{$\begin{array}{l}\text { Study } \\
\text { design }\end{array}$} & \multirow[t]{2}{*}{ DR criteria } & \multicolumn{2}{|c|}{$\begin{array}{l}\text { Patients } \\
\text { evaluated } \\
\text { for DR }\end{array}$} & \multirow[t]{2}{*}{ Anti-TNF } & \multirow[t]{2}{*}{$\begin{array}{l}\text { Concomitant } \\
\text { Therapeutics }\end{array}$} & \multirow[t]{2}{*}{$\begin{array}{l}\text { Time of DR } \\
\text { assessment }\end{array}$} & \multirow[t]{2}{*}{$\begin{array}{l}\text { Prior } \\
\text { Anti-TNF } \\
\text { Use }\end{array}$} \\
\hline & & & & UC & $C D$ & & & & \\
\hline $\begin{array}{l}\text { Kaymak } \\
2018\end{array}$ & Switzerland & Retro & $\begin{array}{l}\mathrm{HBI}<5 \text { or } \\
\mathrm{CDAl}<150, \\
\text { Fcal }<150 \times 2 \\
\text { years, no } \\
\text { ulcerations } \\
\text { (endoscopic } \\
\text { and } \\
\text { histologically) }\end{array}$ & - & 109 & $\mathrm{IFX} X^{\dagger}$ & $\begin{array}{l}\text { Not } \\
\text { specified; } \\
\text { steroid } \\
\text { refractory }\end{array}$ & 2 year & $\begin{array}{l}\text { Yes } \\
(11 / 109 \\
\text { prior } \\
\text { ADA) }\end{array}$ \\
\hline $\begin{array}{l}\text { Kumar } \\
2018\end{array}$ & UK & Retro & $\begin{array}{l}\mathrm{CR}+\mathrm{ER} \\
\text { (undefined) }\end{array}$ & 56 & - & Golimumab & $\begin{array}{l}\mathrm{IMM}^{\S} \\
(36 / 56)\end{array}$ & 1 year & $\begin{array}{l}\text { Not } \\
\text { specifiec }\end{array}$ \\
\hline $\begin{array}{l}\text { Munoz- } \\
\text { Villafranca } \\
2018\end{array}$ & Spain & Pro & $\begin{array}{l}\text { pMayo } 0-2, \\
\text { endo Mayo } \\
0-1\end{array}$ & 53 & - & $\mathrm{ADA}^{\ddagger}$ & $\begin{array}{l}\text { IMM§ } \\
(38 / 53)\end{array}$ & $\begin{array}{l}8 \text { weeks, } \\
1 \text { year }\end{array}$ & No \\
\hline
\end{tabular}

All studies originated in Europe with the exception of Yu 2015, Dai 2014, and Zhang 2016. ${ }^{18,20,21}$ Nine studies were prospective in design, ${ }^{16,18,19,21,23,24,27-29}$ and seven were carried out at multiple institutions. ${ }^{16,17,19,20,23,24,30}$ No phase IV trials were identified for inclusion. Two studies defined deep remission (DR) beyond the minimum criteria of clinical remission and endoscopic remission - Magro 2016 included histologic remission defined as a Geboe's score < 4, and Kaymak 2018 supplemented both histologic remission and two years of biochemical remission (fecal calprotectin < 150). ${ }^{22,} 24$ Two conference abstracts used the same cohort and reported rates of DR at different time points, therefore this cohort was only counted one time. ${ }^{27,28}$ Ten studies featured only infliximab (IFX), ${ }^{16,18,20-22,24,26-29}$ two used only adalimumab (ADA), ${ }^{19,23}$ one study assessed golimumab, ${ }^{30}$ and two studies incorporated both IFX and ADA. ${ }^{17,25}$ Pineton de Chambrun 2016 reported that $65 \%$ of DR patients received concomitant therapy with AZA, whereas only $28 \%$ of their non-DR group was receiving concomitant AZA. Other studies did not specify concomitant therapy use. Most included studies did not specify the number of cases with perianal or fistulizing disease, precluding additional statistics for this sub-population of patients. Similarly, the majority of studies evaluating CD did not clearly indicate if patients were pre-operative, though most were TNF naïve. No studies reported use of biosimilar agents. The heterogeneities of studies are reported (Supplementary Table 1).

\subsection{Quality of studies and risk of bias}

The Newcastle Ottawa Scale (NOS) was used to evaluate and assign a point value to each study for quality and risk of bias (Supplementary Table 2). ${ }^{13}$ Studies received a point for "adequacy of follow up of cohorts" if their reported outcomes accounted for attrition. All included studies received between five and six points on the NOS, suggesting that they carried an intermediate risk of bias. Two studies, De Vos 2013 and Zhang 2016, included patients already in clinical remission, additional sensitivity analyses were run with these studies excluded (Supplementary Fig. 1). ${ }^{16,21}$

\subsection{Achieving deep remission at 8 weeks, 6 months, 1 year, and 2 years}

Four studies reported a combined $36.4 \%$ (95\% Cl: $12.6-69.4 \%)$ rate (86/230 patients) of achieving DR at eight weeks. $20,23,24,29$ Four studies reported the rate of DR at six months, ${ }^{19,21,24,28}$ with $39.1 \%$ (95\% Cl: $10.4-78.0 \%$ ), or $62 / 155$ patients, achieving the treatment target (Fig. 2). Of these four studies, Zhang 2016 only included patients already in clinical remission. ${ }^{21}$ Sensitivity analysis with Zhang 2016 removed demonstrated a 32.8\% rate of deep remission at six months (Supplementary Fig. 1). Funnel plots (Supplementary Fig. 2) and Egger's test for both eight weeks and six months did not detect publication bias (eight week: Egger's t-value 0.056, $p=0.480$; six month: Egger's t-value $=2.002, p=0.091$ ). 
Nine studies reported the rate of DR at one-year follow-up, ${ }^{16,18,19,21,23-25,27,30}$ with $44.4 \%$ (95\% Cl: $34.6-54.6 \%$ ) of patients (285/616) achieving DR. Five studies reported rates of DR at two years, with $36 \%$ (95\% Cl: $18.7-58 \%$ ) of patients (182/490) in DR

(Fig. 2). ${ }^{17,19,21,22,26}$ For one year, De Vos 2013 and Zhang 2016 only included patients already in clinical remission. ${ }^{16,21}$ Sensitivity analysis with Zhang 2016 and De Vos 2013 removed demonstrated a 42.3\% rate of deep remission at one year, and sensitivity analysis with Zhang 2016 removed at two year analysis had a deep remission rate of $27.8 \%$ (Supplementary Fig. 1). Funnel plots (Supplementary Fig. 2) and Egger's test at one-year and two-years did not demonstrate publication bias (one year: Egger's t-value = $0.703, p=0.252$; two years: Egger's $t$-value $=0.673, p=0.275$ ).

\subsection{Achieving deep remission in Crohn's disease and ulcerative colitis}

Crohn's Disease (CD): Ten studies reported rates of DR in 769 patients with CD between eight weeks and 2 years. ${ }^{17-22,25-28}$ At eight weeks, one study reported $18.9 \%$ DR. ${ }^{20}$ DR at six months was reported by three studies to be $7.8 \%$ (Echarri 2015), 59.1\% (Zhang 2016), and 79.6\% (Vadan 2013). ${ }^{19,21,28}$ DR at two years was reported by five studies to be $43.2 \%$ (Molander 2013), 37.5\% (Echarri 2015), 77.3\% (Zhang 2016), 7.3\% (Kaymak 2018), and 29.9\% (Pineton de Chambrun 2016). ${ }^{17,} 19,21,22,26$ DR in CD was reported at one year by five studies (Fig. 3) and found to be $48.6 \%$ (95\% Cl: $32.8-64.7 \%$ ) in 139/293 patients. ${ }^{18,19,21,25,27}$ Sensitivity analysis with Zhang 2016 removed resulted in a $42.1 \%$ rate of deep remission (Supplementary Fig. 1). Funnel plot and Egger's test did not demonstrate publication bias.

Ulcerative Colitis (UC): Seven studies reported the rate of DR in 353 UC patients between eight weeks and 2 years. ${ }^{16-18,23,24,29,30}$ DR at eight weeks was reported in three studies to be 43.4\% (Munoz-Villafranca 2018), ${ }^{23} 10 \%$ (Magro 2016), ${ }^{24}$ and $80.4 \%$ (Prymak 2016). ${ }^{29}$ DR at six months was reported in one study (Magro 2016) to be $25 \% .{ }^{24}$ DR at two years was reported in one study (Molander 2013) to be $62.3 \% .{ }^{17}$ DR in UC was reported at one-year by five studies (Fig. 3) and found to be $43.6 \%$ (95\% Cl: $32.8-$ $55.1 \%$ ) in 146/323 patients. ${ }^{16,18,23,24,30}$ Sensitivity analysis with De Vos 2013 removed resulted in a $46.6 \%$ deep remission rate at one year (Supplementary Fig. 1). Funnel plot and Egger's test did not demonstrate publication bias.

\subsection{Deep remission in biologic naïve patients}

Ten studies specifically indicated that patients were naïve to, or not previously treated with, biologic treatments. ${ }^{16,19-21,23,24,26-29}$

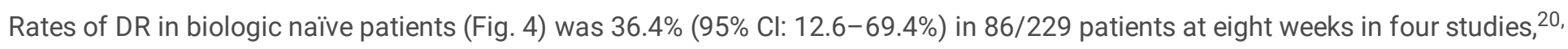
$23,24,2939.1 \%$ (95\% Cl: $10.4-78 \%$ ) in 62/155 patients at 6 months in four studies, ${ }^{19,}, 21,24,2847.2 \%$ (95\% Cl: $\left.34.5-60.4 \%\right)$ in $129 / 284$ patients at one year in six studies, ${ }^{16,19}, 21,23,24,27$ and $46.7 \%$ (95\% Cl: $23.9-71 \%$ ) in 52/129 patients at two years in three studies. ${ }^{19,21,26}$ Funnel plot and Egger's tests did not demonstrate publication bias except for 2 years (Egger's t-value = 8.607, $p=$ 0.037).

\subsection{Deep remission in patients treated with infliximab}

The majority of studies primarily included patients treated with infliximab (IFX), therefore additional analyses excluding studies which did not utilize infliximab were conducted to determine rates of DR with IFX. Meta-analysis excluding Sebkova 2012, Kumar 2018, Echarri 2015, and Munoz-Villafranca 2018 demonstrated an IBD deep remission rate of $48.6 \%$ at one year (Fig. 5). Sensitivity analysis at two years with the non-IFX studies Echarri 2015 removed, and excluding non-IFX cases from Molander 2013, resulted in a deep remission rate of $36.8 \%$ (Fig. 5). Sensitivity analysis with Echarri 2015 removed found a $51.5 \%$ rate of deep remission in CD at one year in patient's receiving infliximab (Fig. 5). Analysis of deep remission in UC at one year demonstrated a rate of $39.9 \%$ with non-infliximab studies removed (Fig. 5).

\section{Discussion}

The ongoing development of novel targeted therapeutics has improved our ability to achieve clinical and endoscopic remission. While the efficacy of anti-TNFa agents achieving clinical remission has been established, evidence suggests that deep remission 
(DR) provides more durable remission. ${ }^{3-5}$ Newer guidelines provided by the American College of Gastroenterology (ACG) and the International Organization for the Study of Inflammatory Bowel Disease (IOIBD) recommend mucosal healing with clinical remission as preferred treatment targets in $\mathrm{UC}$ and $\mathrm{CD} .{ }^{31-33}$ With the introduction of newer therapies such as ustekinumab, vedolizumab, tofacitinib, in addition to anti-TNFa agents, patients and gastroenterologists have more personalized treatment options suitable for long-term use. Therapeutics should be continued despite achieving deep remission, as withdrawal of therapy after achieving DR is associated with high rate of relapse. ${ }^{2}$ Therefore, while efficacy of an agent is important, other factors including side-effect profile, cost, clinician experience, patient preference and comorbidities, and availability should be considered. ${ }^{34}$

Anti-TNFa agents, the oldest and most well-studied biologic class in the treatment of IBD, carry multiple advantages over alternative biologics. In addition to their superior clinical efficacy, long-term outcomes and side-effect profiles are well described, and systemic effect enables the concurrent treatment of rheumatologic diseases. Furthermore, infliximab is available as biosimilars and adalimumab allows the option of administration via injectables. ${ }^{35,36}$ With regards to efficacy, a 2018 meta-analysis of RCTs estimated the efficacy of infliximab and adalimumab in achieving remission in CD. ${ }^{37}$ Furthermore, a more recent 2020 review and network meta-analysis of RCTs estimated outcomes consistent with deep remission in UC using infliximab, adalimumab, and ustekinumab. $^{7}$

Real-world data (RWD), though acquired via cohort studies rather than randomized controlled trials, offers complementary information, providing generalizable clinical efficacy that can be compared to results reported by RCTs. Utility of this data has recently been demonstrated by the VICTORY consortium, established to evaluate the efficacy of vedolizumab in CD and UC patients based on RWD gathered retrospectively from multiple institutions. ${ }^{38,39}$ GEMINI 1 reported a $41.8-44.8 \%$ rate of remission (Mayo < $=2$, no subscore $>1$ ) at 52 weeks, similar to the $41 \%$ rate of endoscopic remission (Mayo subscore $=0$ ), clinical remission rate of $51 \%$, and deep remission rate of $30 \%$ at 1 year follow-up reported by the VICTORY Consortium. ${ }^{39,40}$ While significant differences in study design and patient enrollment exist between GEMINI and VICTORY precluding direct comparison, the findings highlight the relevance of RWD for clinical decision-making and for directing future therapeutic research.

Our meta-analysis of fifteen real world studies of anti-TNFa use in CD and UC demonstrates that RWD DR rates supplement rates reported in existing phase III trial data and provides data in the setting of a potential efficacy-effectiveness gap. Though no clinically significant difference can be derived from the data, we demonstrate a modestly higher observed rate of DR in UC in realworld studies. We report a DR rate of $48.6 \%$ at one year in CD using RWD, providing similar results compared to a previous metaanalysis of RCTs. ${ }^{37}$ These results confirm the findings of prior RCTs with regards to efficacy of anti-TNFs. An additional observation was that the rate of DR after one year of treatment was higher than earlier time points; following this peak, DR rates diminished by two years, demonstrating that the greatest therapeutic benefit from anti-TNFa is likely realized within the first 12 months. In subanalysis, the rate of DR in anti-TNFa naïve patients at one year was $47.2 \%$ (95\% Cl: 34.5-60.4\%), similar to the DR rate at one year in all patients. Finally, we observe a small increase in the rate of deep remission when only including studies that evaluated response to infliximab.

This meta-analysis with systematic review is the first to comprehensively report DR with anti-TNFa agents based on RWD, using a strictly pre-defined definition of DR as clinical remission combined with endoscopic remission. We thoroughly reviewed the literature by incorporating results from Pubmed and EMBASE in addition to conference abstracts and review of references from publications. We additionally report remission rates at predefined time points. The inclusion of only RWD provides clinical effectiveness data in clinical practice settings, complementary and comparable to results reported by RCTs. ${ }^{11}$ We anticipate the findings will help guide clinical decision making and elucidate the generalizability of these treatments to diverse and heterogenous populations.

There are several limitations. Constrained by available studies, we could not directly compare differences in DR rates between CD and UC. The limitation in number of available studies also precluded analysis of CD and UC at the eight week, six month, and two year time points. Most studies utilized infliximab, therefore we were unable to provide a head-to-head comparison of biologic agents. We attempted to account for heterogeneity of biologics with additional analyses including only studies conducted with infliximab. Furthermore, paucity of available publications precluded the inclusion of newer therapeutic options. Additionally, we recognize that there are varying definitions and sources of RWD, and therefore elected to use definitions and sources similar to those used in recent meta-analyses of RWD. ${ }^{38,39}$ Heterogeneity attributing to study design, use of cohort studies rather than RCTs, 
varying severity of disease in included patients, variations in concomitant medication usage, and differences in defining DR and endoscopic remission and were expected given the utilization of RWD.

In conclusion, our systematic review with meta-analysis of real-world data assessing deep remission from anti-TNFa utilization demonstrated the highest success at 52 -weeks, with nearly $45 \%$ of patients reaching this treatment target. Future studies on the real-world efficacy of newer therapeutic options are needed to validate their efficacy in day-to-day practice.

\section{Abbreviations}

clinical remission (CR), deep remission (DR), endoscopic remission (ER), mucosal healing (MH), randomized control trial (RCT), realworld data (RWD)

\section{Declarations}

\section{Ethics Approval and consent to participate}

This manuscript reflects a systematic review and meta-analysis, ethics or institutional review board approval was waived for this study.

\section{Consent for publication}

Not applicable

\section{Availability of data and materials}

All data generated or analysed during this study are included in this published article and its supplementary information files.

\section{Competing interests}

The authors declare they have no competing interests.

\section{Funding}

Bing Zhang is supported by funding from the National Institutes of Health, grant number 5T32DK007007-45.

\section{Author's contributions}

All the listed co-authors have contributed to, read, and agreed to submission of the final manuscript. OA contributed to study concept and design, data acquisition, and significant drafting of the manuscript. AG contributed to study concept and design, acquisition of data, and revision of manuscript. LS contributed to study design, provided critical revision of the manuscript, and study supervision. BZ contributed to study concept and design, analysis and interpretation of data, statistical analysis, funding, drafting of manuscript, and serves as the guarantor of the manuscript.

\section{Disclosures:}

The authors of this manuscript have no financial, professional, or personal disclosures to report.

\section{References}


1. Colombel JF, Louis E, Peyrin-Biroulet L, et al. Deep remission: a new concept? Dig Dis. 2012;30 Suppl 3:107-11. doi:10.1159/000342732

2. Zhang B, Gulati A, Alipour O, Shao L. Relapse from deep remission after therapeutic de-escalation in inflammatory bowel disease: a systematic review and meta-analysis. J Crohns Colitis. Apr 2020;doi:10.1093/ecco-jcc/jjaa087

3. D'haens G, Van Deventer S, Van Hogezand R, et al. Endoscopic and histological healing with infliximab anti-tumor necrosis factor antibodies in Crohn's disease: A European multicenter trial. Gastroenterology. May 1999;116(5):1029-34. doi:10.1016/s0016-5085(99)70005-3

4. Geboes K, Rutgeerts P, Opdenakker G, et al. Endoscopic and histologic evidence of persistent mucosal healing and correlation with clinical improvement following sustained infliximab treatment for Crohn's disease. Curr Med Res Opin. Nov 2005;21(11):1741-54. doi:10.1185/030079905×65457

5. Colombel JF, Rutgeerts PJ, Sandborn WJ, et al. Adalimumab induces deep remission in patients with Crohn's disease. Clin Gastroenterol Hepatol. Mar 2014;12(3):414-22.e5. doi:10.1016/j.cgh.2013.06.019

6. Zallot C, Peyrin-Biroulet L. Deep remission in inflammatory bowel disease: looking beyond symptoms. Curr Gastroenterol Rep. Mar 2013;15(3):315. doi:10.1007/s11894-013-0315-7

7. Singh S, Murad MH, Fumery M, et al. First- and Second-line Pharmacotherapies for Patients with Moderate to Severely Active Ulcerative Colitis: An Updated Network Meta-Analysis. Clin Gastroenterol Hepatol. Jan 2020;doi:10.1016/j.cgh.2020.01.008

8. Eichler HG, Abadie E, Breckenridge A, et al. Bridging the efficacy-effectiveness gap: a regulator's perspective on addressing variability of drug response. Nat Rev Drug Discov. 07 2011;10(7):495-506. doi:10.1038/nrd3501

9. Freemantle N, Strack T. Real-world effectiveness of new medicines should be evaluated by appropriately designed clinical trials. J Clin Epidemiol. Oct 2010;63(10):1053-8. doi:10.1016/j.jclinepi.2009.07.013

10. Ha C, Ullman TA, Siegel CA, Kornbluth A. Patients enrolled in randomized controlled trials do not represent the inflammatory bowel disease patient population. Clin Gastroenterol Hepatol. Sep 2012;10(9):1002-7; quiz e78. doi:10.1016/j.cgh.2012.02.004

11. Rudrapatna VA, Butte AJ. Opportunities and challenges in using real-world data for health care. J Clin Invest. Feb 2020;130(2):565-574. doi:10.1172/JCI129197

12. Moher D, Liberati A, Tetzlaff J, et al. Preferred reporting items for systematic reviews and meta-analyses: the PRISMA statement. Ann Intern Med. Aug 2009;151(4):264-9, W64. doi:10.7326/0003-4819-151-4-200908180-00135

13. Wells G, Shea B, O'Connell D, et al. The Newcastle-Ottawa Scale (NOS) for assessing the quality of nonrandomised studies in meta-analyses. 2000.

14. DerSimonian R, Laird N. Meta-analysis in clinical trials. Control Clin Trials. Sep 1986;7(3):177-88. doi:10.1016/01972456(86)90046-2

15. Higgins JP, Thompson SG, Deeks JJ, Altman DG. Measuring inconsistency in meta-analyses. BMJ. Sep 2003;327(7414):55760. doi:10.1136/bmj.327.7414.557

16. De Vos M, Louis EJ, Jahnsen J, et al. Consecutive fecal calprotectin measurements to predict relapse in patients with ulcerative colitis receiving infliximab maintenance therapy. Inflamm Bowel Dis. Sep 2013;19(10):2111-7.

doi:10.1097/MIB.0b013e31829b2a37

17. Molander P, Sipponen T, Kemppainen $\mathrm{H}$, et al. Achievement of deep remission during scheduled maintenance therapy with TNFa-blocking agents in IBD. J Crohns Colitis. Oct 2013;7(9):730-5. doi:10.1016/j.crohns.2012.10.018

18. Dai C, Liu WX, Jiang M, Sun MJ. Mucosal healing did not predict sustained clinical remission in patients with IBD after discontinuation of one-year infliximab therapy. PLoS One. 2014;9(10):e110797. doi:10.1371/journal.pone.0110797

19. Echarri A, Ollero V, Barreiro-de Acosta M, et al. Clinical, biological, and endoscopic responses to adalimumab in antitumor necrosis factor-naive Crohn's disease: predictors of efficacy in clinical practice. Eur J Gastroenterol Hepatol. Apr 2015;27(4):430-5. doi:10.1097/MEG.0000000000000296

20. Yu L, Yang X, Xia L, et al. Infliximab preferentially induces clinical remission and mucosal healing in short course Crohn's disease with luminal lesions through balancing abnormal immune response in gut mucosa. Mediators Inflamm. 2015;2015:793764. doi:10.1155/2015/793764

21. Zhang T, Wang Z, Fan R, et al. The Efficacy of Infliximab Monotherapy versus Infliximab-Azathioprine Sequential Treatment in Crohn's Disease: Experience from a Tertiary Medical Center in China. Biomed Res Int. 2016;2016:8648307. 
doi:10.1155/2016/8648307

22. Kaymak T, Moriconi F, Niess JH, et al. Low Discontinuation Rate of Infliximab Treatment in Steroid-Dependent/Refractory Crohn's Disease Patients. Inflamm Intest Dis. Mar 2018;2(3):171-179. doi:10.1159/000486676

23. Muñoz-Villafranca C, Ortiz de Zarate J, Arreba P, et al. Adalimumab treatment of anti-TNF-naïve patients with ulcerative colitis: Deep remission and response factors. Dig Liver Dis. Aug 2018;50(8):812-819. doi:10.1016/j.dld.2018.03.007

24. Magro F, Lopes SI, Lopes J, et al. Histological Outcomes and Predictive Value of Faecal Markers in Moderately to Severely Active Ulcerative Colitis Patients Receiving Infliximab. J Crohns Colitis. Dec 2016;10(12):1407-1416. doi:10.1093/ecco$\mathrm{jcc} / \mathrm{jjw} 112$

25. Sebkova L, Rodino S, D'Amico T, Saka N. Predictive Factors of Deep Remission Achievement in Patients With Crohn's Disease Treated With Anti-TNF Alfa. Gastroenterology2012. p. S-228.

26. Pineton de Chambrun G, Libier L, Collins M, et al. Evaluation and Long-Term Benefit of Deep Remission in Crohn's Disease Patients Treated With Infliximab. Gastroenterology2016. p. S810-S811.

27. Vadan R, Gheorghe L, Gheorghe C, Suciu S. Silent endoscopic relapse in patients with clinical maintained remission and previous deep remission on scheduled treatment with infliximab. Journal of Crohn's and Colitis2012. p. S158.

28. Vadan R, Gheorghe L, Cerban R, et al. Deep remission: a recurrent feature in patients with Crohn's disease and long term biologic therapy. presented at: European Crohn's and Colitis Organisation; 2013; Session Poster. https://doi.org/10.1016/S1873-9946(13)60569-3

29. O P. The efficacy of initial treatment with infliximab without previous conventional therapy in patients with moderate-to-severe ulcerative colitis. presented at: European Crohn's and Colitis Organisation; 2016; Session Poster. https://doi.org/10.1093/eccojcc/jjw019.483

30. Kumar A, Slater J, Jones J, et al. Golimumab in ulcerative colitis: A multi-centre real-world experience. presented at: European Crohn's and Colitis Organisation; 2018; Session Poster. https://doi.org/10.1093/ecco-jcc/jjx180.747

31. Peyrin-Biroulet L, Sandborn W, Sands BE, et al. Selecting Therapeutic Targets in Inflammatory Bowel Disease (STRIDE): Determining Therapeutic Goals for Treat-to-Target. Am J Gastroenterol. Sep 2015;110(9):1324-38. doi:10.1038/ajg.2015.233

32. Rubin DT, Ananthakrishnan AN, Siegel CA, et al. ACG Clinical Guideline: Ulcerative Colitis in Adults. Am J Gastroenterol. Mar 2019;114(3):384-413. doi:10.14309/ajg.0000000000000152

33. Lichtenstein GR, Loftus EV, Isaacs KL, et al. ACG Clinical Guideline: Management of Crohn's Disease in Adults. Am J Gastroenterol. 04 2018;113(4):481-517. doi:10.1038/ajg.2018.27

34. Danese S, Vuitton L, Peyrin-Biroulet L. Biologic agents for IBD: practical insights. Nat Rev Gastroenterol Hepatol. Sep 2015;12(9):537-45. doi:10.1038/nrgastro.2015.135

35. Papamichael K, Lin S, Moore M, Papaioannou G, Sattler L, Cheifetz AS. Infliximab in inflammatory bowel disease. Ther Adv Chronic Dis. 2019;10:2040622319838443. doi:10.1177/2040622319838443

36. Stevenson M, Archer R, Tosh J, et al. Adalimumab, etanercept, infliximab, certolizumab pegol, golimumab, tocilizumab and abatacept for the treatment of rheumatoid arthritis not previously treated with disease-modifying antirheumatic drugs and after the failure of conventional disease-modifying antirheumatic drugs only: systematic review and economic evaluation. Health Technol Assess. 04 2016;20(35):1-610. doi:10.3310/hta20350

37. Singh S, Fumery M, Sandborn WJ, Murad MH. Systematic review and network meta-analysis: first- and second-line biologic therapies for moderate-severe Crohn's disease. Aliment Pharmacol Ther. 08 2018;48(4):394-409. doi:10.1111/apt.14852

38. Dulai PS, Singh S, Jiang X, et al. The Real-World Effectiveness and Safety of Vedolizumab for Moderate-Severe Crohn's Disease: Results From the US VICTORY Consortium. Am J Gastroenterol. 08 2016;111(8):1147-55. doi:10.1038/ajg.2016.236

39. Narula N, Peerani F, Meserve J, et al. Vedolizumab for Ulcerative Colitis: Treatment Outcomes from the VICTORY Consortium. Am J Gastroenterol. 09 2018;113(9):1345. doi:10.1038/s41395-018-0162-0

40. Feagan BG, Rutgeerts P, Sands BE, et al. Vedolizumab as induction and maintenance therapy for ulcerative colitis. NEng/ J Med. Aug 2013;369(8):699-710. doi:10.1056/NEJMoa1215734

\section{Figures}

Page $11 / 14$ 


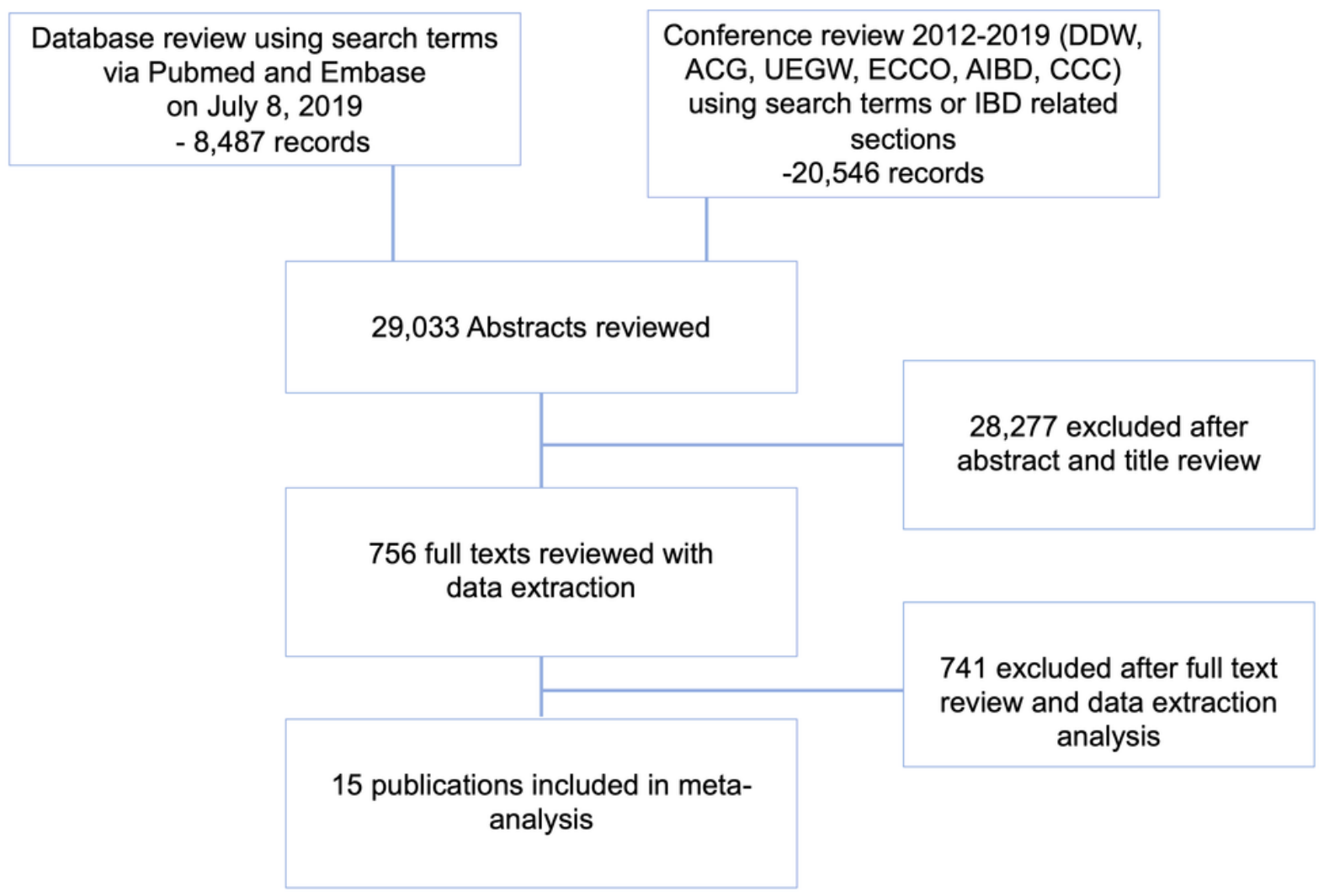

Figure 1

PRISMA diagram.

$\begin{array}{cccccc}\text { Studies } & \text { Estimate }(95 \% & \text { Weight } & \text { DR/Total } & \text { Studies } & \text { Estimate (95\% Cl) Weight }\end{array}$

Deep remission in IBD at 8 weeks

\begin{tabular}{lrrr} 
Yu 2015 & $18.9(12.5-27.4)$ & 26.67 & $20 / 106$ \\
Prymak 2016 & $80.4(67.3-89.1)$ & 25.80 & $41 / 51$ \\
Magro 2016 & $10(2.5-32.4)$ & 21.07 & $2 / 20$ \\
$\begin{array}{l}\text { Munoz- } \\
\text { Villafranca 2018 }\end{array}$ & $43.4(30.8-56.9)$ & 26.46 & $23 / 53$ \\
& & & \\
\hline Overall & $36.4(12.6-69.4)$ & $86 / 230$
\end{tabular}

Deep remission in IBD at 6 months

\begin{tabular}{lccc} 
Vadan 2013 & $79.6(66.1-88.7)$ & 25.61 & $39 / 49$ \\
Echarri 2015 & $7.8(3.3-17.4)$ & 24.85 & $5 / 64$ \\
Zhang 2016 & $59.1(38.2-77.2)$ & 25.09 & $13 / 22$ \\
Magro 2016 & $25(10.8-47.8)$ & 24.45 & $5 / 20$ \\
\hline Overall & $39.1(10.4-78)$ & & $62 / 155$
\end{tabular}
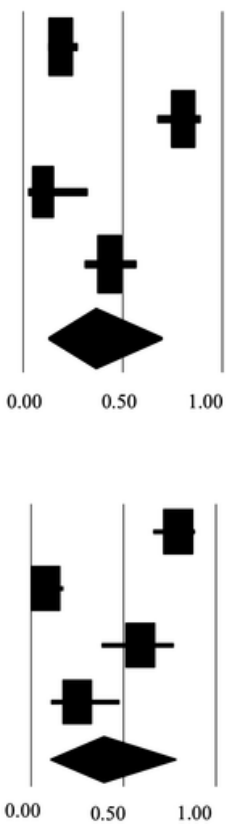

Deep remission in IBD at 1 year

$\begin{array}{lcccc}\text { Sebkova 2012 } & 23.3(14.3-35.6) & 11.29 & 14 / 60 \\ \text { Vadan 2012 } & 49(35.4-62.7) & 11.64 & 24 / 49 \\ \text { De Vos 2013 } & 34.5(25.3-45) & 12.67 & 30 / 87 \\ \text { Dai 2014 } & 55.6(48.9-62) & 13.89 & 120 / 216 \\ \text { Echarri 2015 } & 39.6(27.5-53.2) & 11.72 & 21 / 53 \\ \text { Zhang 2016 } & 81.8(60.4-93) & 7.29 & 18 / 22 \\ \text { Magro 2016 } & 25(10.8-47.8) & 7.80 & 5 / 20 \\ \text { Kumar } & 39.3(27.5-52.5) & 11.85 & 22 / 56 & 31 / 53 \\ \text { Munoz-Villafranca } & 58.5(44.9-70.9) & 11.76 & 285 / 616 & \end{array}$

Deep remission in IBD at 2 years

\begin{tabular}{lcccc|} 
Molander 2013 & $48.4(42.3-54.6)$ & 22.01 & $122 / 252$ \\
Echarri 2015 & $37.5(24-53.2)$ & 20.09 & $15 / 40$ \\
Zhang 2016 & $77.3(55.6-90.2)$ & 17.53 & $17 / 22$ \\
$\begin{array}{l}\text { Pineton de } \\
\text { Chambrun 2016 }\end{array}$ & $29.9(20.1-41.8)$ & 20.80 & $20 / 67$ \\
Kaymak 2018 & $7.3(3.7-14)$ & 19.56 & $8 / 109$
\end{tabular}

Figure 2 
Rates of deep remission in IBD at eight weeks, six months, one year, and two years.

\begin{tabular}{lcccc} 
Studies & Estimate (95\% Cl) & Weight & DR/Total \\
Crohn's Disease one year deep remission & & \\
Sebkova 2012 & $23.3(14.3-35.6)$ & 20.48 & $14 / 60$ \\
Vadan 2012 & $49(35.4-62.7)$ & 20.91 & $24 / 49$ \\
Dai 2014 & $56.9(47.5-65.8)$ & 22.76 & $62 / 109$ \\
Echarri 2015 & $39.6(27.5-53.2)$ & 21.02 & $21 / 53$ \\
Zhang 2019 & $81.8(60.4-93)$ & 14.83 & $18 / 22$ \\
\hline Overall & $48.6(32.8-64.7)$ & & $139 / 293$ \\
Ulcerative colitis one year deep remission & & & \\
De Vos 2013 & $34.5(25.3-45)$ & 22.74 & $30 / 87$ \\
Dai 2014 & $54.2(44.7-63.4)$ & 24.05 & $58 / 107$ \\
Magro 2016 & $25(10.8-47.8)$ & 12.04 & $5 / 20$ \\
Kumar 2018 & $39.3(27.5-52.5)$ & 20.69 & $22 / 56$ \\
Munoz-Villafranca & $58.5(44.9-70.9)$ & 20.48 & $31 / 53$ \\
2018 & $43.6(32.8-55.1)$ & & $146 / 323$ \\
\hline Overall & & & \\
& & &
\end{tabular}

\section{Figure 3}

Rates of deep remission in Crohn's disease and ulcerative colitis at one year.

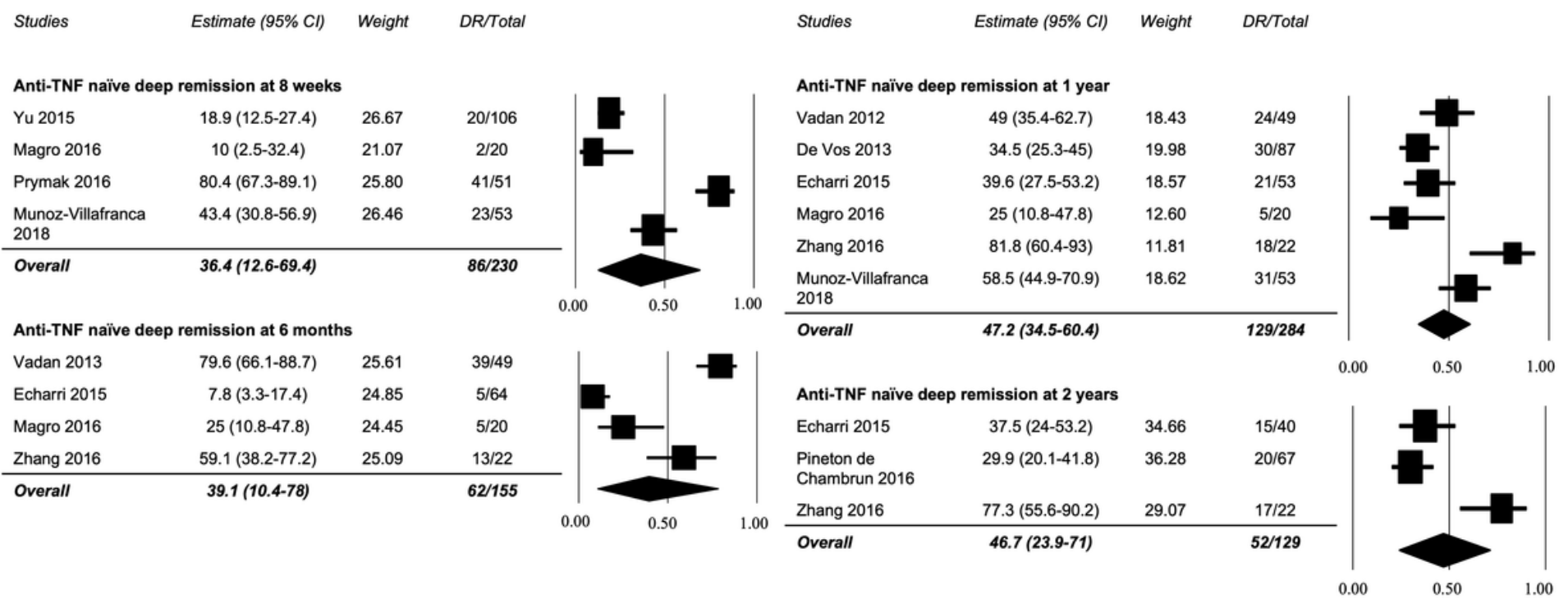


Rates of deep remission in IBD in anti-TNF naïve patients at eight weeks, six months, one year, and two years.

Meta-Analysis: Deep remission rates with inflibimab

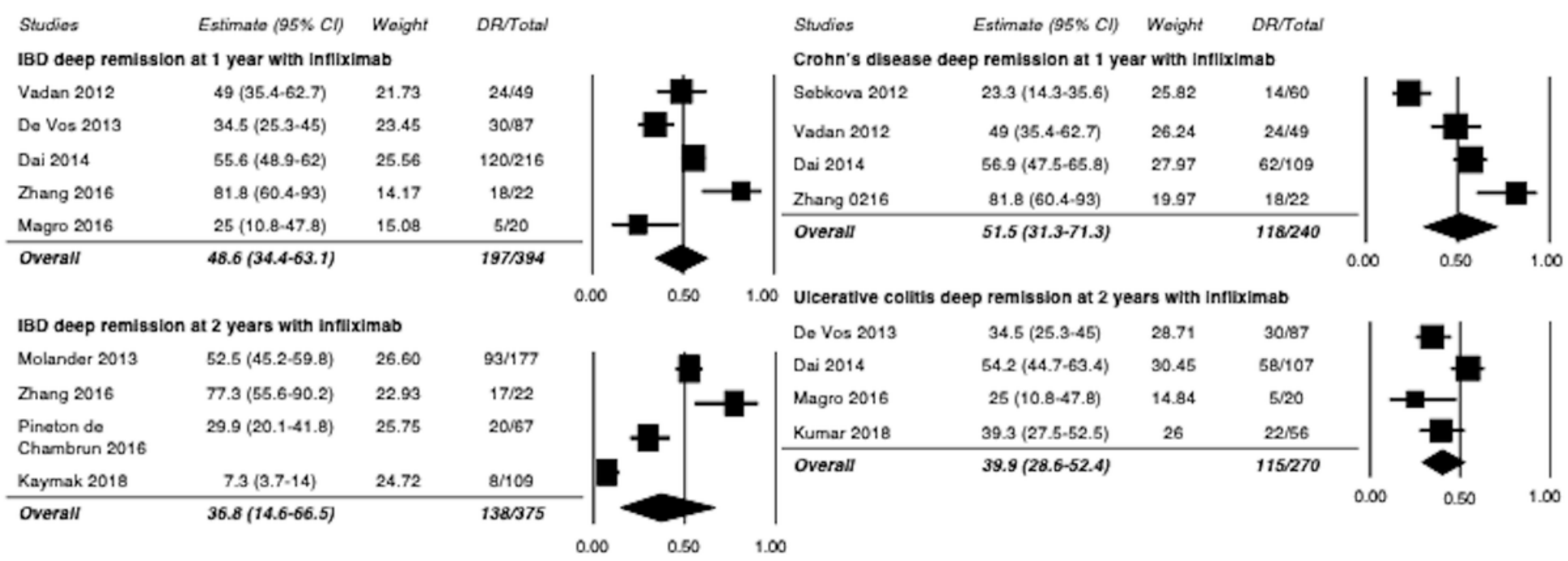

Figure 5

Rates of deep remission in IBD and CD/UC sub-categories with infliximab

\section{Supplementary Files}

This is a list of supplementary files associated with this preprint. Click to download.

- FS1SensitivityAnalysisCRremovedfiguretiff.tiff

- FigureS2FunnelPlotachievingDR.tiff

- TextSupplemental1 searchstrategy.docx

- SuppTables.docx 